\title{
Non-Invasive Assessment of Intravascular Pressure Gradients: A Review of Current and Proposed Novel Methods
}

\author{
Tin-Quoc Nguyen ${ }^{1,2, *}$, Kristoffer Lindskov Hansen ${ }^{1,2}$, Thor Bechsgaard $\left.{ }^{3}{ }^{(}\right)$, Lars Lönn ${ }^{1,2}$, \\ Jørgen Arendt Jensen ${ }^{4}$ and Michael Bachmann Nielsen ${ }^{1,2}$ (D) \\ 1 Department of Diagnostic Radiology, Copenhagen University Hospital, Blegdamsvej 9, 2100 Copenhagen, \\ Denmark; lindskov@gmail.com (K.L.H.); lonn.lars@gmail.com (L.L.); mbn@dadlnet.dk (M.B.N.) \\ 2 Department of Clinical Medicine, University of Copenhagen, Blegdamsvej 3B, 2200 Copenhagen, Denmark \\ 3 Department of Radiology, Odense University Hospital Svendborg Hospital, Baagøes Alle 31, \\ 5700 Svendborg, Denmark; thorbechsgaard@gmail.com \\ 4 Center for Fast Ultrasound Imaging, DTU Elektro, Technical University of Denmark, Ørsteds Plads Building \\ 349, 2800 Lyngby, Denmark; jaj@elektro.dtu.dk \\ * Correspondence: tinqnguyen@gmail.com; Tel.: +45-60-14-15-46
}

Received: 29 October 2018; Accepted: 26 December 2018; Published: 29 December 2018

\begin{abstract}
Invasive catheterization is associated with a low risk of serious complications. However, although it is the gold standard for measuring pressure gradients, it induces changes to blood flow and requires significant resources. Therefore, non-invasive alternatives are urgently needed. Pressure gradients are routinely estimated non-invasively in clinical settings using ultrasound and calculated with the simplified Bernoulli equation, a method with several limitations. A PubMed literature search on validation of non-invasive techniques was conducted, and studies were included if non-invasively estimated pressure gradients were compared with invasively measured pressure gradients in vivo. Pressure gradients were mainly estimated from velocities obtained with Doppler ultrasound or magnetic resonance imaging. Most studies used the simplified Bernoulli equation, but more recent studies have employed the expanded Bernoulli and Navier-Stokes equations. Overall, the studies reported good correlation between non-invasive estimation of pressure gradients and catheterization. Despite having strong correlations, several studies reported the non-invasive techniques to either overestimate or underestimate the invasive measurements, thus questioning the accuracy of the non-invasive methods. In conclusion, more advanced imaging techniques may be needed to overcome the shortcomings of current methods.
\end{abstract}

Keywords: pressure gradient; ultrasound; magnetic resonance imaging; intravascular catheterization; review

\section{Introduction}

Intravascular pressure gradients are important to monitor to understand the cardiovascular system. High gradients across stenotic heart valves may cause symptoms and disability, or even death [1]. The gold standard is an invasive procedure involving fluoroscopy for guidance, but noninvasive cost-effective alternative techniques are needed [2-5]. Vascular access for diagnostic and therapeutic procedures can be performed through various vessels with the femoral artery, radial artery, and jugular vein being the most widely used access sites [6,7]. Two main pathways exist for invasive measurements: fluid-filled catheters that transmit pressure-waves to an external pressure sensitive transducer [8,9], or directly on the pressure sensitive tip of a pressure wire [9]. 
Invasive catheterization is associated with various complications, such as bloodstream infections [10], neurological deficits [11], hematomas and pneumothorax [6]. Additionally, intravascular tools may narrow the vessel lumen, and ultimately interfere with the measurements $[9,12,13]$. Catheterization is considered unsuitable for regular follow-up [14] and is not recommended for routine diagnostic pressure assessment $[15,16]$.

Alternatives to invasive methods are pressure gradients obtained with imaging, such as ultrasound (US) and magnetic resonance imaging (MRI). By using different equations, acquired velocity estimations can be converted to pressure gradients [17-21]. The aim of this paper was to review in vivo studies of non-invasively derived pressure gradients compared with invasive methods to assess the performance of non-invasive pressure gradient estimation in the literature.

\section{Literature Search}

A literature search on non-invasive techniques was performed in PubMed on 19 December, 2018, using the following search criteria: (("Pressure"[Mesh] OR "Blood Pressure"[Mesh] OR "Blood Pressure Determination"[Mesh] OR “Arterial Pressure"[Mesh]) AND “Diagnostic Imaging"[Mesh]) AND ("Catheterization" OR "Catheterisation"). This resulted in 3978 papers that were narrowed down to 338 papers by adding the following search criteria: ("Pressure gradient" OR "Pressure drop" OR "Pressure difference").

The papers were screened by title and abstract. Inclusion criteria were English language and comparisons of non-invasive pressure gradient estimation versus invasive methods, in vivo. Full-text reading was done on the selected papers and additional relevant studies found from the reference list of these papers were included. In total, 38 publications were included in this review.

\section{From Images to Pressure Gradients}

Blood accelerates when passing through a stenosis [17]. The conversion of potential energy to kinetic energy results in a high flow velocity and a drop in pressure [22]. As the diameter widens distal to a stenosis, flow decelerates and pressure rises again, albeit to a lower pressure level than initially, as some kinetic energy is removed due to viscous losses and the formation of turbulences [22]. Pressure gradients cannot be measured directly with imaging modalities. Yet, velocities can be obtained and used to calculate pressure gradients. The most commonly used formulas to calculate pressure gradients from velocities are the simplified Bernoulli equation and the Navier-Stokes equations.

The Bernoulli equation is derived from the principle of conservation of energy [18] and is used to convert velocities to pressure gradients. By assuming peak velocities are acquired, that a large difference in proximal and distal velocity is present, and by neglecting viscous losses, the equation is expressed by the simplified Bernoulli equation as

$$
\Delta p=4 \times v_{2}^{2}
$$

where $\Delta p$ is the pressure gradient and $v^{2}$ is the measured peak velocity in the stenosis $[17,18]$. The simplified Bernoulli equation has several shortcomings due to the assumptions made. Firstly, it cannot be used if the distal velocity approaches the proximal velocity. Secondly, it is inaccurate for narrow and long stenoses, where viscous losses are significant [18]. Thirdly, flow is assumed to be laminar in one direction with a constant velocity, and thus neglects the complexity of hemodynamics [23]. Additionally, the equation may result in overestimation of the invasively measured pressure gradient, if the downstream invasive measurement is not performed close to the stenosis [18].

If the distal velocity approaches the proximal velocity, the proximal velocity can no longer be neglected, and $v^{2}$ has to be replaced with the distal and proximal velocities. This can be expressed by the expanded Bernoulli equation as

$$
\Delta p=4 \times\left(v_{2}^{2}-v_{1}^{2}\right)
$$


where $v^{2}$ is the distal flow velocity, and $v^{1}$ the proximal velocity [18].

The Navier-Stokes equations describe flow hemodynamics more accurately than the Bernoulli equation [23] and can be used to calculate pressure gradients from velocity fields. Fluids are assumed to be incompressible and Newtonian [24]. The equations are derived from the laws of mass conservation and linear momentum [19-21] and can be expressed as

$$
-\nabla p=\rho\left(\frac{\partial \mathrm{v}}{\partial \mathrm{t}}+v \times \nabla v-g\right)-\mu \nabla^{2} v
$$

where $p$ is pressure, $\rho$ is fluid density, $\partial \mathrm{v} / \partial \mathrm{t}$ is temporal acceleration, $\nabla$ is divergence, $v$ is velocity, $\mu$ is fluid viscosity, and $g$ is the gravitational force. The Bernoulli equation is a simplification of the Navier-Stokes equations [23], as it neglects the temporal acceleration, the viscous losses and the gravitational forces. The Navier-Stokes equations do not make these assumptions, but require an increased amount of measurements of the full velocity field for estimating pressure gradients [25].

\section{Imaging Modalities}

Both the Bernoulli and the Navier-Stokes equations depend on flow velocities being measured to calculate pressure gradients across stenoses. Blood flow velocities can be obtained non-invasively with different medical imaging techniques, i.e., MRI and US.

\subsection{Magnetic Resonance Imaging}

MRI is a non-invasive imaging modality depicting detailed anatomical structures without using ionizing radiation [26,27]. MRI utilizes the changes in hydrogen-nuclei being exposed to radiofrequency signals inside a strong magnetic field.

Flow velocities can be obtained with Phase Contrast MRI (PC-MRI), which measures the phase shift of moving spins [28]. The net phase shift is proportional to the flow velocity (Figure 1) [29,30].
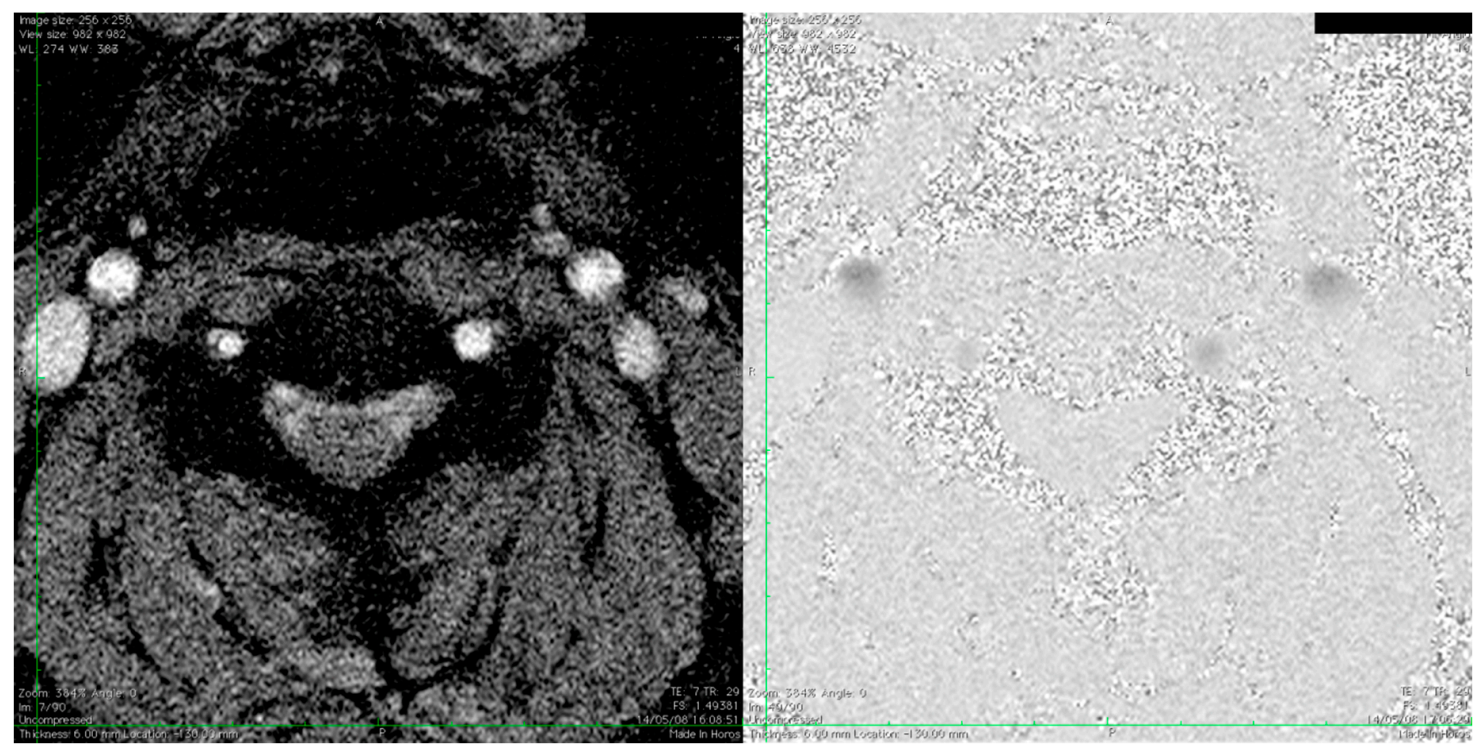

Figure 1. The left image shows a time-of-flight image of the neck in the transverse scan plane. The image is used for identifying and marking the carotid arteries for velocity estimation with phase contrast MRI. The right image shows the phase contrast image using a through-plane sequence. Images were provided by co-author Kristoffer Lindskov Hansen.

MRI is widely considered the gold standard for estimation of flow velocity and volume flow [31-34]. MRI is known to have high spatial resolution (approximately $100 \mu \mathrm{m}$ ) and good contrast for tissue differentiation, but drawbacks are that MRI is expensive, relatively time consuming and 
can be difficult to perform on patients with certain metallic foreign bodies or claustrophobia [35-37]. Additionally, conventional cardiac PC-MRI is gated with electro-cardiogram and has to be performed over multiple cardiac cycles, but alternative MRI-techniques are emerging, allowing for real-time velocity estimation [38].

\subsection{Ultrasound}

US is a non-invasive imaging modality capable of producing real-time visualization of anatomical structures without adverse effects [39]. Sound waves are emitted from the US transducer, and the strength of the sound waves reflected back depends on the tissue medium they have interacted with. Flow velocities can be obtained with Doppler US by examining the change in frequency of the returning sound wave. The movement of red blood cells in flowing blood increase or decrease the frequency of emitted sound waves depending on their flow direction, and the measured blood velocity is proportional to the returning shift in Doppler frequency [40].

US is a portable, real-time diagnostic imaging modality with low expenses, with high spatial resolution $(2.5 \mu \mathrm{m})$, and high temporal resolution [39,41]. Limitations include a small field of view, angle dependent velocity estimation and suboptimal insonation windows [15,42-44]. Guidelines recommend using continuous wave Doppler US for measuring peak velocities and peak pressure gradients across aortic and tricuspid valves $[15,45]$, as the technique allows for evaluation of higher velocities than pulsed wave Doppler (Figure 2). However, a disadvantage of using continuous wave Doppler US is that no information of depth is obtained, as the acquired peak velocity can be from anywhere along the interrogation line [46].

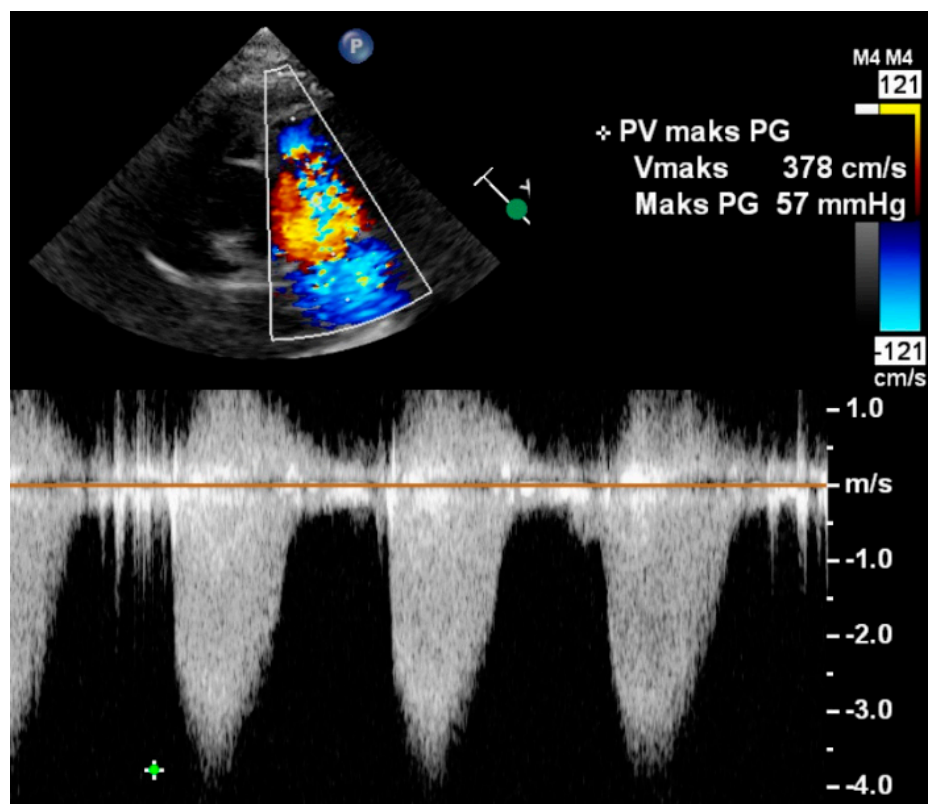

Figure 2. Continuous wave Doppler ultrasound of flow across the pulmonary valve in a patient with pulmonary valve stenosis. Peak pressure gradient ("Maks PG") shown in upper right corner of the screen was calculated in real-time from peak velocity by using the simplified Bernoulli equation. Image was provided by Klaus Juul (Department of Pediatric Cardiology, Copenhagen University Hospital, Denmark).

\section{Estimation of Pressure Gradients in the Heart and the Larger Thoracic Arteries}

The recommended initial imaging modality for diagnosing diseases in the cardiovascular system is transthoracic echocardiography $[16,45,47]$, though MRI is also widely used for imaging of the chest $[48,49]$. In this section, results from studies of the cardiovascular system evaluating the accuracy of estimated pressure gradients compared with invasively measured pressure gradients will be reviewed. 


\subsection{Aortic and Mitral Valves}

Valve area is included in the reference measurement for assessing aortic valve stenosis severity and estimated with transthoracic echocardiography using planimetry [16]. However, the severity of a stenosis cannot be evaluated from this measurement alone. Other parameters like the transvalvular peak velocity and peak pressure gradient must also be considered. The transvalvular estimated pressure gradient is a robust measure and is used as a prognostic indicator [22,50]. Several studies have evaluated the accuracy of transvalvular estimated pressure gradient derived from Doppler US using the simplified Bernoulli equation (Equation (1)) by comparing with an invasively measured pressure gradient. Studies conducted between the late 1970s and 1980s reported strong correlations between estimated and invasively measured pressure gradients for both aortic and mitral valve stenosis $(r=0.72$ to 0.97$)[17,42,46,51-56]$, with the majority reporting the estimated pressure gradients to underestimate the invasively measured ones $[17,42,46,51,52]$. Inaccurate angling between Doppler beam and peak blood flow velocity was suggested as the main reason for this. Hatle et al. found the underestimation to be more pronounced in patients $>50$ years old and suggested that anatomical changes, such as valve deformity and calcifications, could induce a greater variation in peak flow direction [52].

Contrarily, other studies reported the estimated pressure gradients to overestimate the invasively measured values (mean bias: +0.4 to $+19 \mathrm{mmHg}$ ) [57-59]. Overestimation by Doppler US was suggested to be caused by a phenomenon called "pressure recovery" [57,58], by which the discrepancy between the methods is caused by improper placement of the catheter during measurement of the distal intravascular pressure [18]. The distal pressure should ideally be measured with the catheter placed immediately downstream of the stenosis, as the increase in pressure does not occur immediately after passing a stenosis, but will instead happen as a steady increase downstream [58].

Baumgartner et al. suggested a method to correct for pressure recovery and reported both "non-corrected estimated pressure gradients" and "corrected estimated pressure gradients" to correlate strongly with invasively measured pressure gradients ( $n=21 ; r=0.93$ to 0.97$)$ [58]. The authors reported non-corrected estimated pressure gradients to significantly overestimate the invasively measured ones (mean bias: $+18 \mathrm{mmHg}$ ), while the corrected estimated pressure gradients did not (mean bias: $+0.4 \mathrm{mmHg}$ ). However, when Yamazawa et al. applied the suggested correction to their velocity data obtained with Doppler US, mean bias for estimated pressure gradients changed from overestimating, when non-corrected, to instead underestimating the invasive measurements, when corrected $(r=0.87$ to 0.79 , mean bias: $+8.5 \mathrm{mmHg}$ to $-9.1 \mathrm{mmHg}$ ) [60]. Eichenberger et al. examined 10 patients with aortic valve stenosis and three healthy subjects using Doppler US, PC-MRI and cardiac catheterization, and found estimated pressure gradients from both imaging modalities to correlate strongly with invasively measured pressure gradients ( $n=13$, Doppler US: $r=0.96$; PC-MRI: $r=0.97$ ) [61]. The pressure gradients were calculated by applying the simplified Bernoulli equation (Equation (1)) to estimated peak velocities.

\subsection{Pulmonary Arteries}

Patients suspected of pulmonary arterial hypertension are examined with transthoracic echocardiography to estimate the systolic pressure in the pulmonary artery, which is achieved by summating the pressure gradient across the tricuspid valve with the right atrial pressure [45]. In echocardiography, the tricuspid pressure gradient is obtained by applying the simplified Bernoulli equation (Equation (1)) to the tricuspid regurgitation velocity [45,62]. Hioka et al. reported estimated pressure gradients derived from Doppler US across the tricuspid valve to correlate well with invasively measured pressure gradients with a small mean bias $(n=55, r=0.73, p<0.001$; mean bias: $+2.5 \mathrm{mmHg}$ ) [63]. The bias became more pronounced the more severe the stenosis was [63]. Right atrial pressure is approximated by measuring the respiratory variation of the diameter of the inferior vena cava during a sniff maneuver. However, estimation of right atrial pressure by visually evaluating the inferior vena cava has limited precision [64,65]. Magnino et al. reported the average accuracy between 
non-invasive estimation of right atrial pressure and invasive pressures measured during right heart catheterization to be $34 \%$ [65].

The accuracy of echocardiography for pulmonary hypertension diagnosis was evaluated in a meta-analysis by Janda et al. [66]. The authors reported a moderate correlation between echocardiography and invasive catheterization (summary correlation coefficient: 0.70 ). The metaanalysis included 29 studies that compared pulmonary arterial hypertension assessed with Doppler US with the invasively measured pressures of right heart catheterization in 1998 patients. However, $41 \%$ of the patients had suboptimal tricuspid regurgitation velocities, which could potentially result in underestimation of the tricuspid pressure gradient. Because of the limitations, it was concluded that echocardiography should not be recommended as a stand-alone modality for pulmonary hypertension diagnosis.

Nogami et al. used PC-MRI to estimate pressure gradients across the tricuspid valve in 20 patients by applying the simplified Bernoulli equation (Equation (1)) to peak regurgitant velocities [67]. The estimated pulmonary artery systolic pressure strongly correlated with values obtained during right heart catheterization $(n=20, r=0.94, p<0.0001)$.

\subsection{Coarctation of the Aorta}

Transthoracic echocardiography, cardiac MRI, and cardiac computed tomography (CT) are the recommended methods for diagnosing patients suspected of coarctation, while cardiac catheterization is reserved for intravascular treatment [47]. Intervention is indicated if invasive peak-to-peak pressure gradient is measured to be greater than $20 \mathrm{mmHg}$, but may be less than $20 \mathrm{mmHg}$ if radiological evidence of coarctation is significant. Studies evaluating the accuracy of estimated pressure gradients have shown varying results. Strong correlations were reported between Doppler US derived pressure gradients calculated with the expanded Bernoulli equation (Equation (2)) and pressure gradients measured with invasive catheterization $(n=32 ; r=0.98$ and $n=28 ; r=0.76)$ [8,68]. When the simplified Bernoulli equation (Equation (1)) was used, correlations remained strong $(r=0.91$ and $r=0.74)[8,68]$. Contrarily, several other studies have found the correlation between estimated and invasively measured pressure gradients to be weak ( $r=0.35$ to 0.47 ) [69-71], and the published results for estimating pressure gradient with Doppler US in aortic coarctation are diverse.

Oshinski et al. estimated pressure gradients from PC-MRI data and reported superior accuracy compared with estimated values derived from Doppler US, when compared with invasively measured pressure gradients [72]. No correlation coefficient between the methods was reported, and only a minority of the patients had invasive catheterization performed, i.e., 6 out of 32 patients. Pressure gradients have also been estimated from PC-MRI data using computational fluid dynamics simulations [73-76]. Simulated fluid motions based on Navier-Stokes equations have been reported to agree well with invasively measured pressure gradients before $(r=0.97, p=0.00$ and $r=0.85, p<0.001)$ and after dilation of aortic coarctation $(r=0.87, p=0.00)[75,76]$.

\subsection{Coronary Arteries}

Coronary CT angiography is the initial method for low-risk patients suspected of having coronary artery disease [77], thus replacing the conventional diagnostic coronary angiography with a non-invasive imaging modality. However, CT angiography is only used for mapping and characterizing anatomy and not for hemodynamic assessment.

Deng et al. published a study on PC-MRI data in flow phantoms for pressure estimation in the coronary arteries using the Navier-Stokes equations, and a strong correlation between estimated and invasively measured pressure gradients was reported $(r=0.97)$ [78]. When the technique was applied to patients, the pressure gradient was observed to increase exponentially with increasing stenosis severity. The paper did not report a correlation coefficient for the patient study. The limited amount of MRI-studies investigating the accuracy of pressure gradients in the coronary arteries, may be due to several obstacles: Viscous losses become more significant in small vessels, making the simplified 
Bernoulli (Equation (1)) equation less useful [79]. Furthermore, cardiac and respiratory motion, and the small size of the vessels, all affect the assessment of flow [78,80,81].

Likewise, only few studies have investigated the use of US for coronary arteries. Artifacts caused by calcifications, adjacency to the lung, cardiac, and respiratory motion, and the branching nature of the coronary arteries, all contribute to making it difficult to evaluate these vessels with US [82-84]. No studies investigating the use of Doppler US for estimating pressure gradients in the coronary arteries were found.

\section{Estimation of Pressure Gradients in Carotids and Peripheral Vessels}

Comparative studies between non-invasive estimation of pressure gradients and catheterization have also been performed in vessels outside the thoracic region. Doppler US, CT angiography, and MRI angiography are all recommended as diagnostic imaging methods for assessing the severity of peripheral artery disease [85]. Invasive angiography is only indicated, when non-invasive methods are inconclusive, or when revascularization is clinically indicated. Correlations were reported to be weak to moderate for the carotid arteries, when Illig et al. compared invasively measured pressure gradients with estimated pressure gradients derived from Doppler US using the simplified $(n=77$, $r=0.419, p<0.0001)$ (Equation (1) $)$ and the expanded Bernoulli equation $(n=77, r=0.374, p=0.0008)$ (Equation (2)) [86]. Doppler US studies of the iliac arteries have reported results to be diverse with correlations ranging from weak to strong. In studies that applied the expanded Bernoulli equation (Equation (2)), the estimated pressure gradient was found to overestimate and to correlate from weakly to moderately with invasively measured values $(n=261, r=0.27$ and $n=33, r=0.54)[87,88]$. De Smet et al. suggested the low correlation to be caused by a large Doppler angle secondary to the course of the iliac arteries [87]. Langsfeld et al. and Strauss et al. used the simplified Bernoulli equation (Equation (1)) and reported the correlation between estimated and invasively measured pressure gradients to be strong, when performed on the iliac arteries $(n=23, r=0.9, p<0.01$ and $n=28$, $r=0.76, p<0.0001)[89,90]$.

Several animal studies have evaluated the accuracy of non-invasive methods in peripheral vessels. Pressure gradients have been calculated by applying the Navier-Stokes equations to PC-MRI data in surgically created cerebral aneurysms [91], carotid stenoses [80,92] and renal artery stenoses $[80,93]$ resulting in an overall strong correlation with invasive catheterization ( $r=0.82$ to 0.95$)$.

The referenced papers in this section are listed in Table 1. 
Table 1. Shows a list of included studies in this review. "Simultaneous Doppler US" involved Doppler US to be performed simultaneously with catheterization. "Instantaneous gradients" is the correlation between a maximum Doppler US or MRI derived pressure gradient compared with an invasive pressure gradient measured using a dual-head catheter, which allowed for simultaneous invasive pressure measurement before and after a stenosis. "Peak-to-peak" is the correlation between maximum Doppler US or MRI derived pressure gradient compared with an invasive pressure gradient measured between the peak pressures before and after a stenosis. "Peak gradient" did not clearly specify how invasive pressure gradients were measured. "Mean gradient" is the correlation between a Doppler US or MRI derived mean pressure gradient compared with an invasively measured mean pressure gradient. * A correlation coefficient for the post-treatment comparison was not reported.

\begin{tabular}{|c|c|c|c|c|c|}
\hline Study & Year & Country & Study Population (Subjects) & Methods Used & Results \\
\hline \multicolumn{6}{|c|}{ Aortic and Mitral Valve } \\
\hline Hatle et al. [17] & 1978 & Norway & $\begin{array}{l}\text { Mitral valve stenosis }(n=35) \\
\text { Other valve lesions }(n=20)\end{array}$ & $\begin{array}{l}\text { Simultaneous Doppler US and simultaneous } \\
\text { left and right heart catheterization. } \\
\text { Doppler US before and after simultaneous } \\
\text { left and right heart catheterization. }\end{array}$ & $\begin{array}{l}\text { Reports good correlation between Doppler } \\
\text { US and catheter gradients }\end{array}$ \\
\hline Hegrenaes et al. [42] & 1985 & Norway & Aortic valve stenosis $(n=87)$ & Doppler US and catheter pullback & Reported underestimation by Doppler US \\
\hline Stamm et al. [46] & 1983 & USA & $\begin{array}{l}\text { Aortic valve stenosis }(n=26) \\
\text { Mitral valve stenosis }(n=27)\end{array}$ & $\begin{array}{l}\text { Doppler US and simultaneous left } \\
\text { ventricular and femoral artery } \\
\text { catheterization. }\end{array}$ & $\begin{array}{l}\text { Aortic valve stenosis: } r=0.95 \\
\text { Mitral valve stenosis: } r=0.85\end{array}$ \\
\hline Knutsen et al. [51] & 1982 & Norway & Mitral valve stenosis $(n=16)$ & $\begin{array}{l}\text { Simultaneous Doppler US and simultaneous } \\
\text { left and right heart catheterization. }\end{array}$ & $\begin{array}{l}\text { Mean gradient: } r=0.83 \\
\text { Mean difference: }-4.9 \mathrm{mmHg}\end{array}$ \\
\hline Hatle et al. [52] & 1980 & Norway & Aortic valve stenosis $(n=37)$ & Doppler US and catheterization & $\begin{array}{l}\text { Reported underestimation by Doppler US in } \\
8 \text { out of } 37 \text { patients }\end{array}$ \\
\hline Currie et al. [53] & 1985 & USA & Aortic valve stenosis $(n=100)$ & $\begin{array}{l}\text { Simultaneous Doppler US and } \\
\text { dualhead-catheter } \\
\text { Simultaneous Doppler US and catheter } \\
\text { pullback }\end{array}$ & $\begin{array}{l}\text { Mean gradient: } \\
r=0.92, \text { mean difference: }-4 \mathrm{mmHg} \\
\text { Instantaneous gradient: } \\
r=0.92, \text { mean difference: }-19 \mathrm{mmHg} \\
\text { Peak-to-peak gradient: } r=0.91\end{array}$ \\
\hline Currie et al. [54] & 1986 & USA & Cardiac lesions $(n=95)$ & $\begin{array}{l}\text { Simultaneous Doppler US and } \\
\text { dualhead-catheter }\end{array}$ & $\begin{array}{l}\text { Instantaneous gradient: } \\
r=0.95 \text {, mean difference: }-4 \mathrm{mmHg} \\
\text { Peak-to-peak gradient: } r=0.92\end{array}$ \\
\hline Burstow et al. [55] & 1989 & USA & Prosthetic valves $(n=36)$ & $\begin{array}{l}\text { Simultaneous Doppler US and } \\
\text { dualhead-catheter }\end{array}$ & $\begin{array}{l}\text { Mean gradient: } r=0.97 \\
\text { Instantaneous gradient: } r=0.94 \\
\text { Peak-to-peak gradient: } \\
r=0.72 \text {, mean difference: }-1 \mathrm{mmHg}\end{array}$ \\
\hline Yeager et al. [56] & 1986 & USA & Aortic valve stenosis $(n=52)$ & Doppler US and catheter pullback & $\begin{array}{l}\text { Mean gradient: } r=0.87 \\
\text { Peak-to-peak gradient: } r=0.84\end{array}$ \\
\hline
\end{tabular}


Table 1. Cont

\begin{tabular}{|c|c|c|c|c|c|}
\hline Study & Year & Country & Study Population (Subjects) & Methods Used & Results \\
\hline Ohlsson et al. [57] & 1986 & Sweden & Aortic valve stenosis $(n=24)$ & $\begin{array}{l}\text { Doppler US and simultaneous aortic arch } \\
\text { and left ventricle catheterization }\end{array}$ & $\begin{array}{l}\text { Mean gradient: } r=0.92 \\
\text { Instantaneous gradient: } r=0.89\end{array}$ \\
\hline $\begin{array}{l}\text { Baumgartner et al. } \\
{[58]}\end{array}$ & 1999 & Austria & Aortic valve stenosis $(n=21)$ & Doppler US and dualhead-catheter & $\begin{array}{l}\text { Non-corrected instantaneous gradient: } \\
r=0.95 \text {, mean difference: }+18 \mathrm{mmHg} \\
\text { Corrected instantaneous gradient: } \\
r=0.97 \text {, mean difference: }+0.4 \mathrm{mmHg} \\
\text { Non-corrected mean gradient: } \\
r=0.93 \text {, mean difference: }+12 \mathrm{mmHg} \\
\text { Corrected mean gradient: } \\
r=0.96 \text {, mean difference: }+1.1 \mathrm{mmHg}\end{array}$ \\
\hline VanAuker et al. [59] & 2000 & USA & Aortic valve stenosis $(n=14)$ & $\begin{array}{l}\text { Simultaneous Doppler US and } \\
\text { dualhead-catheter }\end{array}$ & Mean difference: $+42 \%$ \\
\hline Yamazawa et al. [60] & 2010 & Japan & Aortic valve stenosis $(n=13)$ & Doppler US and catheter pullback & $\begin{array}{l}\text { Non-corrected mean gradient: } \\
r=0.98 \text {, mean difference: }+5.7 \mathrm{mmHg} \\
\text { Non-corrected peak-to-peak gradient: } \\
r=0.87 \text {, mean difference: }+8.5 \mathrm{mmHg} \\
\text { Corrected mean gradient: } \\
r=0.91 \text {, mean difference: }-4.9 \mathrm{mmHg} \\
\text { Corrected peak-to-peak gradient: } \\
r=0.79, \text { mean difference: }-9.1 \mathrm{mmHg}\end{array}$ \\
\hline $\begin{array}{l}\text { Eichenberger et al. } \\
{[61]}\end{array}$ & 1993 & Switzerland & Aortic valve stenosis $(n=19)$ & $\begin{array}{l}\text { Doppler US }(n=15) \\
\text { MRI }(n=19) \\
\text { Catheterization }(n=13)\end{array}$ & $\begin{array}{l}\text { Doppler US vs catheter: } r=0.96 \\
\text { MRI vs catheter: } r=0.97\end{array}$ \\
\hline \multicolumn{6}{|c|}{ Pulmonary Hypertension } \\
\hline Hioka et al. [63] & 2017 & Japan & $\begin{array}{l}\text { Patients referred for right heart } \\
\text { catheterization }(n=55)\end{array}$ & Doppler US and catheterization & $\begin{array}{l}\text { Tricuspid gradient: } \\
r=0.73 \text {, mean difference: }+2.52 \mathrm{mmHg}\end{array}$ \\
\hline Fisher et al. [64] & 2009 & USA & Pulmonary hypertension $(n=65)$ & Doppler US and catheterization & $\begin{array}{l}\text { Pulmonary artery systolic pressure: } \\
r=0.66, \text { mean difference: }-0.6 \mathrm{mmHg} \\
\text { Tricuspid mean difference: }-1.8 \mathrm{mmHg}\end{array}$ \\
\hline Janda et al. [66] & 2011 & Canada & Pulmonary hypertension & Meta-analysis & $\begin{array}{l}\text { Pulmonary artery systolic pressure: } \\
r=0.70 \\
\text { Summary sensitivity: } 83 \% \\
\text { Summary specificity: } 72 \%\end{array}$ \\
\hline Nogami et al. [67] & 2009 & Japan & Pulmonary hypertension $(n=20)$ & Doppler US, MRI and catheterization & $\begin{array}{l}\text { Pulmonary artery systolic pressure: } \\
\text { Doppler US vs. catheter: } r=0.86 \\
\text { MRI vs. catheter: } r=0.94\end{array}$ \\
\hline
\end{tabular}


Table 1. Cont

\begin{tabular}{|c|c|c|c|c|c|}
\hline Study & Year & Country & Study Population (Subjects) & Methods Used & Results \\
\hline \multicolumn{6}{|c|}{ Coarctation of Aorta } \\
\hline Syamasundar et al. [8] & 1989 & Saudi Arabia & Coarctation of Aorta $(n=28)$ & Doppler US and catheter pullback & $\begin{array}{l}\text { Simple Bernoulli: } r=0.76 \\
\text { Expanded Bernoulli: } r=0.76\end{array}$ \\
\hline Marx et al. [68] & 1986 & USA & Coarctation of aorta $(n=28)$ & Doppler US and catheter pullback & $\begin{array}{l}\text { Simple Bernoulli: } \\
r=0.91 \text {, mean difference: }+8 \mathrm{mmHg} \\
\text { Expanded Bernoulli: } \\
r=0.98 \text {, mean difference: } 0 \mathrm{mmHg}\end{array}$ \\
\hline Houston et al. [69] & 1987 & Scotland & Coarctation of aorta $(n=46)$ & $\begin{array}{l}\text { Doppler US, catheter pullback, } \\
\text { dualhead-catheter, two catheters }\end{array}$ & $\begin{array}{l}\text { Instantaneous gradient: } r=0.36 \\
\text { Peak-to-peak: } r=0.42\end{array}$ \\
\hline Wisotzkey et al. [70] & 2015 & USA & Aortic arch obstruction $(n=60)$ & Doppler US and catheter pullback & $\begin{array}{l}\text { Simple Bernoulli: } r=0.47 \\
\text { Expanded Bernoulli: } r=0.35\end{array}$ \\
\hline Tang et al. [71] & 2009 & USA & Coarctation of aorta $(n=34)$ & Doppler US and catheter pullback & $\begin{array}{l}\text { Peak-to-peak gradient: } \\
r=0.37, \text { mean gradient: } \\
r=0.001 \\
\text { Reported overestimation of peak pressure } \\
\text { gradient by Doppler US }\end{array}$ \\
\hline Oshinski et al. [72] & 1996 & USA & Coarctation of aorta $(n=32)$ & $\begin{array}{l}\text { Doppler US }(n=22) \\
\text { MRI }(n=22) \\
\text { Catheterization }(n=6)\end{array}$ & $\begin{array}{l}\text { Reported a non-significant difference } \\
\text { between MRI and catheter gradients after } \\
\text { correction after a new suggested model }\end{array}$ \\
\hline Itu et al. [73] & 2013 & USA & Coarctation of aorta $(n=4)$ & $\begin{array}{l}\text { Computer simulation on patient MRI data } \\
\text { and catheterization data }\end{array}$ & $\begin{array}{l}\text { Reported good agreement between MRI and } \\
\text { catheter gradients }\end{array}$ \\
\hline Sotelo et al. [74] & 2015 & France & Coarctation of aorta $(n=7)$ & Simultaneous MRI and catheterization. & $\begin{array}{l}\text { Reported good agreement between MRI and } \\
\text { catheter gradients. }\end{array}$ \\
\hline Goubergrits et al. [75] & 2015 & Germany & Coarctation of aorta $(n=13)$ & $\begin{array}{l}\text { MRI and simultaneous ascending aorta and } \\
\text { femoral catheterization }\end{array}$ & $\begin{array}{l}\text { Peak gradient: Pre-treatment: } r=0.97, \\
\text { Mean difference: }-0.5 \mathrm{mmHg}(p=0.8) \\
\text { Post-treatment: } r=0.87 \\
\text { Mean difference: }+3.0 \mathrm{mmHg}(p=0.00)\end{array}$ \\
\hline Mirzaee et al. [76] & 2017 & Germany & Coarctation of aorta $(n=12)$ & MRI and catheterization & $\begin{array}{l}\text { Pre-treatment: } r=0.85 \\
\text { Mean difference: }-0.58 \mathrm{mmHg}(p=0.64) \\
\text { Post-treatment: } r=N A^{*} \\
\text { Mean difference: }-2.54 \mathrm{mmHg}(p=0.04)\end{array}$ \\
\hline \multicolumn{6}{|c|}{ Coronary Artery } \\
\hline Deng et al. [78] & 2017 & USA & Coronary artery stenosis $(n=6)$ & MRI and catheterization & $\begin{array}{l}\text { Reported a trend between MRI and } \\
\text { catheterization }\end{array}$ \\
\hline
\end{tabular}


Table 1. Cont.

\begin{tabular}{|c|c|c|c|c|c|}
\hline Study & Year & Country & Study Population (Subjects) & Methods Used & Results \\
\hline \multicolumn{6}{|c|}{ Carotid Artery } \\
\hline Illig et al. [86] & 1996 & USA & Carotid artery stenosis $(n=76)$ & $\begin{array}{l}\text { Doppler US, and direct puncture of the } \\
\text { common carotid and internal carotid artery }\end{array}$ & $\begin{array}{l}\text { Simplified Bernoulli: } r=0.374 \\
\text { Expanded Bernoulli: } r=0.419\end{array}$ \\
\hline \multicolumn{6}{|c|}{ Iliac Artery } \\
\hline De Smet et al. [87] & 2000 & Netherlands & Iliac artery stenosis $(n=261)$ & $\begin{array}{l}\text { Doppler US and dual-catheter before and } \\
\text { after treatment. }\end{array}$ & $\begin{array}{l}\text { Instantaneous gradient: } r=0.27 \\
\text { Reported overestimation by Doppler US }\end{array}$ \\
\hline Kohler et al. [88] & 1987 & USA & Iliac artery stenosis $(n=18)$ & Doppler US and catheterization & Expanded Bernoulli: $r=0.54$ \\
\hline Langsfeld et al. [89] & 1988 & USA & Iliac artery stenosis $(n=11)$ & Doppler US and catheter pullback & Pressure gradient: $r=0.9$ \\
\hline Strauss et al. [90] & 1993 & Germany & Iliac artery stenosis $(n=28)$ & Doppler US and catheter pullback & $\begin{array}{l}\text { Mean gradient: } \\
r=0.77, \text { mean difference: }-2 \mathrm{mmHg} \\
\text { Instantaneous gradient: } \\
r=0.80 \text {, mean difference: }-1 \mathrm{mmHg} \\
\text { Peak-to-peak gradient: } \\
r=0.76 \text {, mean difference: }-7 \mathrm{mmHg}\end{array}$ \\
\hline \multicolumn{6}{|c|}{ Animal studies } \\
\hline Lum et al. [80] & 2007 & USA & $\begin{array}{l}\text { Porcine with surgically created } \\
\text { stenosis }(n=12)\end{array}$ & $\begin{array}{l}\text { MRI and dual-catheter in: } \\
\text { Carotid stenosis }(n=12) \\
\text { Renal artery stenosis }(n=9) \\
\text { Iliac stenosis }(n=9)\end{array}$ & $\begin{array}{l}\text { Mean gradients: } \\
\text { Carotid artery: } r=0.891 \\
\text { Renal artery: } r=-0.0815 \\
\text { Iliac artery: } r=0.915 \\
\text { Mean difference for carotid + iliac arteries } \\
+0.86 \mathrm{mmHg}\end{array}$ \\
\hline Moftakhar et al. [91] & 2007 & USA & $\begin{array}{l}\text { Canines with surgically created } \\
\text { carotid bifurcation aneurysm }(n=8)\end{array}$ & MRI and catheterization & Intra-aneurysmal pressures: $r=0.82$ \\
\hline Turk et al. [92] & 2007 & USA & $\begin{array}{l}\text { Canines with surgically created } \\
\text { carotid bifurcation stenosis }(n=6)\end{array}$ & MRI and catheter pullback & Pressure gradient: $r=0.86$ \\
\hline Bley et al. [93] & 2011 & USA & $\begin{array}{l}\text { Porcine with surgically created renal } \\
\text { artery stenosis }(n=12)\end{array}$ & $\begin{array}{l}\text { MRI and two catheters before and after } \\
\text { stenosis }\end{array}$ & $\begin{array}{l}\text { Peak gradient: } r=0.91 \\
\text { Mean gradient: } r=0.98\end{array}$ \\
\hline
\end{tabular}




\section{Discussion}

Catheterization with pressure transducers is considered the gold standard for measuring intravascular pressures, but is an invasive procedure associated with risk of complications and ionizing radiation for guidance. Instead, US has been recommended for hemodynamic assessment of nearly all thoracic vessels, as the method is widely accessible, inexpensive compared with other methods, and provides real-time diagnostic images with an overall strong correlation with invasive measurements in the heart. When image quality of US is insufficient, or if the results do not agree with the clinical findings, MRI can be used as an alternative method to US [16,94]. Both US and MRI are desired methods as they are non-invasive and do not require ionizing radiation for imaging.

Though, non-invasive estimation of pressure gradients is not without limitations. Estimated pressure gradients are calculated from blood flow velocities (Equations (1)-(3)) and are dependent on the velocity estimation to be precise. However, a gold standard for flow velocity estimation has not yet been established [31-34], making the evaluation of the accuracy of non-invasive velocity estimation difficult. Most of the studies comparing non-invasive estimation of pressure gradients with invasive catheterization used the simplified or expanded Bernoulli equation (Equations (1) and (2)) to convert a velocity into a pressure gradient. These equations neglect blood viscosity and pressure recovery, and the results may overestimate invasively measured pressure gradients $[23,72,88,95,96]$. Another source of error is that US produces images in two dimensions, but velocity estimation with Doppler US is only measured in one dimension, making it prone to error due to angle dependency [42,44]. MRI does not encounter this problem, as MRI measures flow velocities in three dimensions, but MRI is performed over multiple cardiac cycles with low temporal resolution, and the accuracy of velocity estimation may decrease further in vessels with large changes in flow velocity [50,97].

Additionally, comparison of non-invasive instantaneous pressure gradients with invasive pressure gradients measured with the peak-to-peak method poses another problem. Pressure gradients measured instantaneously and peak-to-peak will be different, as the pre-stenotic peak pressure does not occur simultaneously with the post-stenotic peak pressure during systole $[7,90]$. As the pre-stenotic pressure reaches its peak, the post-stenotic pressure will still increase [69,90], and thus the peak-to-peak pressure gradient is a non-physiological parameter [7]. The difference in pressure gradient between the peak-to-peak method and the instantaneous method was evaluated by Strauss et al. and Houston et al., who reported the mean differences to be $7 \mathrm{mmHg}(p<0.05 ; r=0.76, p<0.001)$ and $7.5 \mathrm{mmHg}$ ( $2 \mathrm{SD}$ : -45.4 to $30.3 \mathrm{mmHg}$ ), respectively $[69,90]$. Following these findings, studies comparing instantaneous non-invasive pressure gradients with peak-to-peak invasive measurements would be expected to report a positive systematic bias, if the non-invasive method is precise.

Doppler US is routinely used by cardiologists for estimation of blood pressure gradients, so its accuracy has already been widely accepted by many clinicians. Catheterization is still used, when non-invasive methods do not agree with the clinical findings [16]. However, Vecchi et al. reported catheters to overestimate pressure wires by $24 \%$ in vitro [9]. This finding was supported by computer simulations that found the overestimation to be $29 \%$, while the catheter was present in the phantom. When the catheter was removed, the discrepancy in pressure measurement between pressure wire and the computer simulations was reduced to $1.5 \%$. Therefore, using a catheter as a reference standard is questionable, as catheters narrow existing stenoses further and alters flow, thus overestimating the "actual" pressure gradient and disease severity $[9,12,13]$. Comparison of non-invasive methods with an inaccurate measuring method will at best result in it being just as inaccurate. Use of thinner pressure wires in clinical practice still remain less common due to technical complications, increased expenses, and the need for more extensive training of operators [9]. Most studies included in this review have used fluid-filled catheters to measure invasive pressures, and simultaneous invasive catheterization with non-invasive pressure gradient estimation was rarely performed. This resulted in the stenosis being less severe, when the non-invasive pressure gradient was being estimated.

Discrepancies in measurements can lead to undesired consequences. If the invasively measured pressure gradient is assumed to measure the true value and correctly reflect disease severity, 
then inaccurate estimation with non-invasive methods may result in misclassification of severity and can result in an individual being offered the wrong treatment strategy. Fisher et al. defined a pulmonary artery systolic pressure estimate by Doppler to be accurate if it was within $10 \mathrm{mmHg}$ of the catheter measurement [64], but they found the Doppler US to be inaccurate in $48 \%$ of the cases $(n=65)$. Rich et al. reported similar findings, when they used the same criteria for accuracy and reported Doppler US to be inaccurate in $50.6 \%$ of cases $(n=160)$ [98]. However, despite the risk of misclassification, Doppler US is still recommended by multiple guidelines as the first-in-line method to diagnose vascular disease $[16,45,47,85]$, as the availability and ease of use still outweighs the risks and costs of an invasive procedure. The use of non-invasive methods for hemodynamic evaluation in clinical work relies on its ability to detect a clinically significant obstruction and to correctly classify the severity. The daily use of Doppler US by many clinicians is proof that the accuracy of US is within an acceptable threshold, but is ultimately dependent on the clinical context.

Following the advancement in computer technology, more studies have investigated pressure gradients calculated with the Navier-Stokes equations (Equation (3)) using PC-MRI data. None of the studies in this review evaluating estimated pressure gradients derived with Doppler US have used the Navier-Stokes equations.

Olesen et al. suggested a method for estimation of pressure gradients based on the transverse oscillation method (Figure 3) [20,99]. The transverse oscillation method obtains angle-independent two-dimensional vector velocities, and by using either the Navier-Stokes equations (Equation (3)) or the non-steady Bernoulli equation, the authors estimated pressure gradients along plotted streamlines in healthy subjects $[20,100]$. Brandt et al. measured peak velocities with transverse oscillation and conventional Doppler US, and compared the estimates with MRI. Transverse oscillation was reported to be more accurate and precise than Doppler US for velocity estimation [101], which may translate into improved pressure gradient estimation.

Two-dimensional vector velocities may prove to be essential to understand the complex intravascular hemodynamics in circulation [40]. By visualizing and measuring flow in two dimensions rather than one, it may be possible to overcome some of the limitations experienced with conventional Doppler US, e.g., the angle dependency [40]. Unfortunately, out-of-plane motion in the third axis may still occur. Three-dimensional vector velocity estimation using US has been proposed and validated in vivo by Holbek et al. [102], but it has not yet been used for estimating pressure gradients.
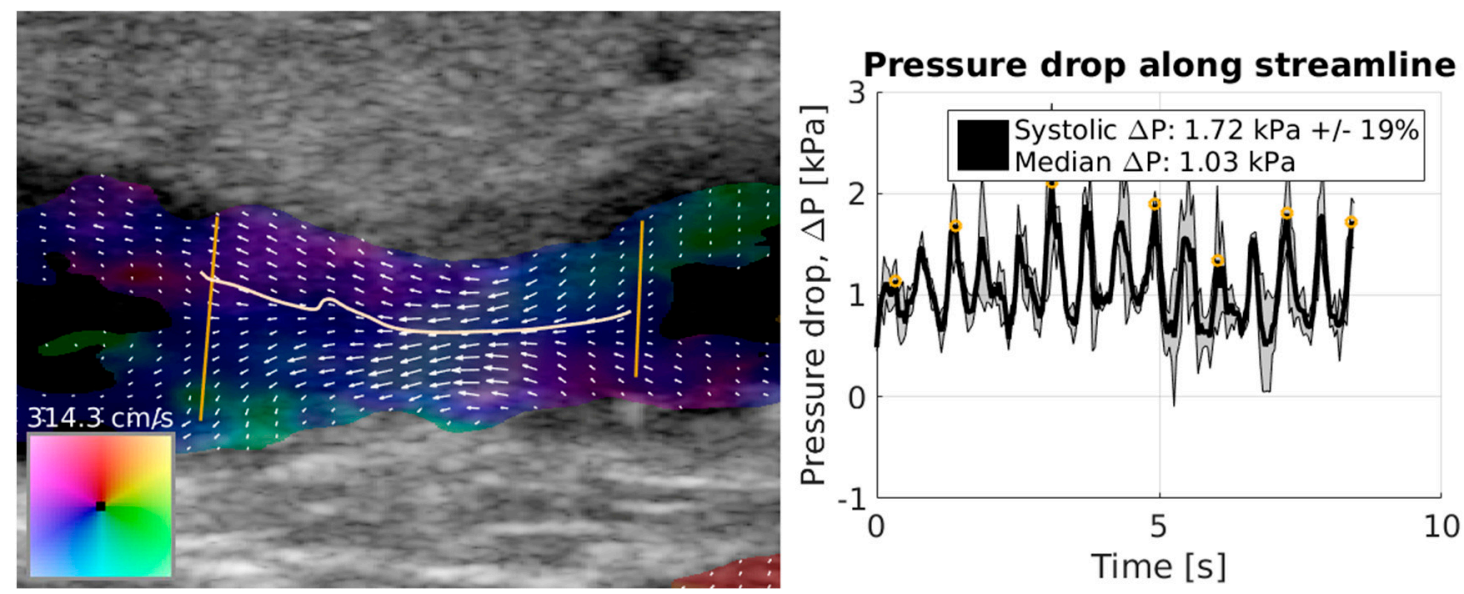

Figure 3. The left image shows vector velocity imaging of an arteriovenous fistula in a patient before intravascular balloon treatment of a stenosis. Arrows and colors represent the two-dimensional vector velocities as indicated by the color-box. Two vertical lines are manually placed, and a streamline representing the highest velocity between the two vertical lines is drawn. The right image shows the peak pressure gradient as a function of time along the plotted streamline over several heartbeats. Both the image and graph were created with an application provided by Jacob B. Olesen (BK Medical, Herlev, Denmark). 


\section{Conclusions}

Overall, pressure gradients estimated with MRI and Doppler US correlate well with invasively measured pressure gradients. However, velocity estimation by Doppler US and calculation of pressure gradients using the simplified Bernoulli equation has several limitations, and future developments should aim for more advanced techniques. Using MRI, vector velocity US or possibly three-dimensional US in combination with the Navier-Stokes equations may provide a more accurate evaluation of flow hemodynamics, assisting the clinician in treatment of cardiovascular disease.

Author Contributions: Conceptualization, T.-Q.N., K.L.H., T.B., L.L., J.A.J. and M.B.N.; investigation, T.-Q.N.; supervision, K.L.H., L.L., J.A.J. and M.B.N.; writing-original draft preparation, T.-Q.N.; writing-review and editing, K.L.H., T.B., L.L., J.A.J. and M.B.N.

Funding: This research received no external funding.

Acknowledgments: The authors would like to acknowledge Klaus Juul (Department of Pediatric Cardiology, Copenhagen University Hospital, Denmark) for providing the image example of continuous wave ultrasound (Figure 2), and Jacob B. Olesen (BK Medical, Herlev, Denmark) for providing the application tool for creating the two-dimensional vector velocity image (Figure 3 ) used in this paper.

Conflicts of Interest: The authors declare no conflict of interest.

\section{References}

1. Carabello, B.A.; Crawford, F.A. Valvular Heart Disease. N. Engl. J. Med. 1997, 337, 32-41. [CrossRef] [PubMed]

2. Chung, E.; Chen, G.; Alexander, B.; Cannesson, M. Non-invasive continuous blood pressure monitoring: A review of current applications. Front. Med. 2013, 7, 91-101. [CrossRef] [PubMed]

3. Deng, Z.; Fan, Z.; Xie, G.; He, Y.; Natsuaki, Y.; Jin, N.; Bi, X.; An, J.; Liu, X.; Zhang, Z.; et al. Pressure gradient measurement in the coronary artery using $4 \mathrm{D}$ PC-MRI: Towards noninvasive quantification of fractional flow reserve. J. Cardiovasc. Magn. Reson. 2014, 16, O55. [CrossRef]

4. Donati, F.; Figueroa, C.A.; Smith, N.P.; Lamata, P.; Nordsletten, D.A. Non-invasive pressure difference estimation from PC-MRI using the work-energy equation. Med. Image Anal. 2015, 26, 159-172. [CrossRef] [PubMed]

5. Ralovich, K.; Itu, L.; Vitanovski, D.; Sharma, P.; Ionasec, R.; Mihalef, V.; Krawtschuk, W.; Zheng, Y.; Everett, A.; Pongiglione, G.; et al. Noninvasive hemodynamic assessment, treatment outcome prediction and follow-up of aortic coarctation from MR imaging. Med. Phys. 2015, 42, 2143-2156. [CrossRef] [PubMed]

6. Hoeper, M.M.; Lee, S.H.; Voswinckel, R.; Palazzini, M.; Jais, X.; Marinelli, A.; Barst, R.J.; Ghofrani, H.A.; Jing, Z.-C.; Opitz, C.; et al. Complications of Right Heart Catheterization Procedures in Patients with Pulmonary Hypertension in Experienced Centers. J. Am. Coll. Cardiol. 2006, 48, 2546-2552. [CrossRef] [PubMed]

7. Nishimura, R.A.; Carabello, B.A. Hemodynamics in the Cardiac Catheterization Laboratory of the 21st Century. Circulation 2012, 125, 2138-2150. [CrossRef]

8. Syamasundar Rao, P.; Carey, P. Doppler ultrasound in the prediction of pressure gradients across aortic coarctation. Am. Heart J. 1989, 118, 299-307. [CrossRef]

9. de Vecchi, A.; Clough, R.E.; Gaddum, N.R.; Rutten, M.C.M.; Lamata, P.; Schaeffter, T.; Nordsletten, D.A.; Smith, N.P. Catheter-Induced Errors in Pressure Measurements in Vessels: An In-Vitro and Numerical Study. IEEE Trans. Biomed. Eng. 2014, 61, 1844-1850. [CrossRef]

10. Mermel, L.A. Prevention of Intravascular Catheter-Related Infections. Ann. Intern. Med. 2000, 132, 391-402. [CrossRef]

11. Omran, H.; Schmidt, H.; Hackenbroch, M.; Illien, S.; Bernhardt, P.; von der Recke, G.; Fimmers, R.; Flacke, S.; Layer, G.; Pohl, C.; et al. Silent and apparent cerebral embolism after retrograde catheterisation of the aortic valve in valvular stenosis: A prospective, randomised study. Lancet 2003, 361, 1241-1246. [CrossRef]

12. Carabello, B.A.; Barry, W.H.; Grossman, W. Changes in arterial pressure during left heart pullback in patients with aortic stenosis: A sign of severe aortic stenosis. Am. J. Cardiol. 1979, 44, 424-427. [CrossRef] 
13. Garcia, L.A.; Carrozza, J.P. Physiologic Evaluation of Translesion Pressure Gradients in Peripheral Arteries: Comparison of Pressure Wire and Catheter-Derived Measurements. J. Interv. Cardiol. 2007, 20, 63-65. [CrossRef]

14. Søndergaard, L.; Ståhlberg, F.; Thomsen, C. Magnetic Resonance Imaging of Valvular Heart Disease. J. Magn. Reson. Imaging 1999, 10, 627-638. [CrossRef]

15. Baumgartner, H.; Hung, J.; Bermejo, J.; Chambers, J.B.; Edvardsen, T.; Goldstein, S.; Lancellotti, P.; LeFevre, M.; Miller, F.; Otto, C.M. Recommendations on the Echocardiographic Assessment of Aortic Valve Stenosis: A Focused Update from the European Association of Cardiovascular Imaging and the American Society of Echocardiography. J. Am. Soc. Echocardiogr. 2017, 30, 372-392. [CrossRef] [PubMed]

16. Baumgartner, H.; Falk, V.; Bax, J.J.; De Bonis, M.; Hamm, C.; Holm, P.J.; Iung, B.; Lancellotti, P.; Lansac, E.; Rodriguez Muñoz, D.; et al. 2017 ESC/EACTS Guidelines for the management of valvular heart disease. Eur. Heart J. 2017, 38, 2739-2791. [CrossRef]

17. Hatle, L.; Brubakk, A.; Tromsdal, A.; Angelsen, B. Noninvasive assessment of pressure drop in mitral stenosis by Doppler ultrasound. Br. Heart J. 1978, 40, 131-140. [CrossRef]

18. Yoganathan, A.P.; Cape, E.G.; Sung, H.W.; Williams, F.P.; Jimoh, A. Review of hydrodynamic principles for the cardiologist: Applications to the study of blood flow and jets by imaging techniques. J. Am. Coll. Cardiol. 1988, 12, 1344-1353. [CrossRef]

19. Yang, G.Z.; Kilner, P.J.; Wood, N.B.; Underwood, S.R.; Firmin, D.N. Computation of flow pressure fields from magnetic resonance velocity mapping. Magn. Reson. Med. 1996, 36, 520-526. [CrossRef]

20. Olesen, J.; Traberg, M.; Pihl, M.; Jensen, J. Noninvasive estimation of 2-D pressure gradients in steady flow using ultrasound. IEEE Trans. Ultrason. Ferroelectr. Freq. Control 2014, 61, 1409-1418. [CrossRef]

21. Liu, X.; Zhang, H.; Ren, L.; Xiong, H.; Gao, Z.; Xu, P.; Huang, W.; Wu, W. Functional assessment of the stenotic carotid artery by CFD-based pressure gradient evaluation. Am. J. Physiol. Heart Circ. Physiol. 2016, 311, H645-H653. [CrossRef] [PubMed]

22. Baumgartner, H.; Hung, J.; Bermejo, J.; Chambers, J.B.; Evangelista, A.; Griffin, B.P.; Iung, B.; Otto, C.M.; Pellikka, P.A.; Quiñones, M.; et al. Echocardiographic assessment of valve stenosis: EAE/ASE recommendations for clinical practice. Eur. J. Echocardiogr. 2009, 10, 1-25. [CrossRef]

23. Donati, F.; Myerson, S.; Bissell, M.M.; Smith, N.P.; Neubauer, S.; Monaghan, M.J.; Nordsletten, D.A.; Lamata, P. Beyond Bernoulli: Improving the Accuracy and Precision of Noninvasive Estimation of Peak Pressure Drops. Circ. Cardiovasc. Imaging 2017, 10, e005207. [CrossRef] [PubMed]

24. Ebbers, T.; Wigström, L.; Bolger, A.F.; Engvall, J.; Karlsson, M. Estimation of relative cardiovascular pressures using time-resolved three-dimensional phase contrast MRI. Magn. Reson. Med. 2001, 45, 872-879. [CrossRef] [PubMed]

25. Canchi, T.; Kumar, S.D.; Ng, E.Y.K.; Narayanan, S. A Review of Computational Methods to Predict the Risk of Rupture of Abdominal Aortic Aneurysms. Biomed. Res. Int. 2015, 2015, 861627. [CrossRef] [PubMed]

26. Fache, J.S. Magnetic resonance imaging. Can. Fam. Phys. 1986, 32, 1087-1090.

27. Berger, A. Magnetic resonance imaging. BMJ 2002, 324, 35. [CrossRef]

28. Moran, P.R. A flow velocity zeugmatographic interlace for NMR imaging in humans. Magn. Reson. Imaging 1982, 1, 197-203. [CrossRef]

29. Bryant, D.J.; Payne, J.A.; Firmin, D.N.; Longmore, D.B. Measurement of flow with NMR imaging using a gradient pulse and phase difference technique. J. Comput. Assist. Tomogr. 1984, 8, 588-593. [CrossRef]

30. Moran, P.R.; Moran, R.A.; Karstaedt, N. Verification and evaluation of internal flow and motion. True magnetic resonance imaging by the phase gradient modulation method. Radiology 1985, 154, 433-441. [CrossRef]

31. Dyverfeldt, P.; Bissell, M.; Barker, A.J.; Bolger, A.F.; Carlhäll, C.-J.; Ebbers, T.; Francios, C.J.; Frydrychowicz, A.; Geiger, J.; Giese, D.; et al. 4D flow cardiovascular magnetic resonance consensus statement. J. Cardiovasc. Magn. Reson. 2015, 17, 72. [CrossRef] [PubMed]

32. Sohns, J.M.; Kowallick, J.T.; Joseph, A.A.; Merboldt, K.D.; Voit, D.; Fasshauer, M.; Staab, W.; Frahm, J.; Lotz, J.; Unterberg-Buchwald, C. Peak flow velocities in the ascending aorta-real-time phase-contrast magnetic resonance imaging vs. cine magnetic resonance imaging and echocardiography. Quant. Imaging Med. Surg. 2015, 5, 685-690. [PubMed] 
33. Bollache, E.; van Ooij, P.; Powell, A.; Carr, J.; Markl, M.; Barker, A.J. Comparison of 4D flow and 2D velocity-encoded phase contrast MRI sequences for the evaluation of aortic hemodynamics. Int. J. Cardiovasc. Imaging 2016, 32, 1529-1541. [CrossRef] [PubMed]

34. Andersson, C.; Kihlberg, J.; Ebbers, T.; Lindström, L.; Carlhäll, C.-J.; Engvall, J.E. Phase-contrast MRI volume flow-A comparison of breath held and navigator based acquisitions. BMC Med. Imaging 2016, 16, 26. [CrossRef] [PubMed]

35. Gerber, A.J.; Peterson, B.S. What is an image? J. Am. Acad. Child. Adolesc. Psychiatry 2008, 47, $245-248$. [CrossRef]

36. Huang, C.-H.; Chen, C.-C.V.; Siow, T.-Y.; Hsu, S.-H.S.; Hsu, Y.-H.; Jaw, F.-S.; Chang, C. High-Resolution Structural and Functional Assessments of Cerebral Microvasculature Using 3D Gas $\triangle \mathrm{R} 2 *$-mMRA. PLoS ONE 2013, 8, e78186. [CrossRef]

37. Saloner, D.; Liu, J.; Haraldsson, H. MR physics in practice: How to optimize acquisition quality and time for cardiac MR imaging. Magn. Reson. Imaging Clin. N. Am. 2015, 23, 1-6. [CrossRef]

38. Sun, A.; Zhao, B.; Li, Y.; He, Q.; Li, R.; Yuan, C. Real-time phase-contrast flow cardiovascular magnetic resonance with low-rank modeling and parallel imaging. J. Cardiovasc. Magn. Reson. 2017, 19. [CrossRef]

39. Patil, P.; Dasgupta, B. Role of diagnostic ultrasound in the assessment of musculoskeletal diseases. Ther. Adv. Musculoskelet. Dis. 2012, 4, 341-355. [CrossRef]

40. Jensen, J.A. Estimation of Blood Velocities Using Ultrasound: A Signal Processing Approach; Cambridge University Press: New York, NY, USA, 1996; ISBN 978-0-521-46484-0.

41. Errico, C.; Pierre, J.; Pezet, S.; Desailly, Y.; Lenkei, Z.; Couture, O.; Tanter, M. Ultrafast ultrasound localization microscopy for deep super-resolution vascular imaging. Nature 2015, 527, 499-502. [CrossRef]

42. Hegrenaes, L.; Hatle, L. Aortic stenosis in adults. Non-invasive estimation of pressure differences by continuous wave Doppler echocardiography. Br. Heart J. 1985, 54, 396-404. [CrossRef] [PubMed]

43. Torok, R.D.; Campbell, M.J.; Fleming, G.A.; Hill, K.D. Coarctation of the aorta: Management from infancy to adulthood. World J. Cardiol. 2015, 7, 765-775. [CrossRef] [PubMed]

44. Bach, D.S. Echo/Doppler evaluation of hemodynamics after aortic valve replacement: Principles of interrogation and evaluation of high gradients. JACC Cardiovasc. Imaging 2010, 3, 296-304. [CrossRef] [PubMed]

45. Galiè, N.; Humbert, M.; Vachiery, J.-L.; Gibbs, S.; Lang, I.; Torbicki, A.; Simonneau, G.; Peacock, A.; Vonk Noordegraaf, A.; Beghetti, M.; et al. 2015 ESC/ERS Guidelines for the Diagnosis and Treatment of Pulmonary Hypertension. Rev. Esp. Cardiol. 2016, 69, 177. [CrossRef] [PubMed]

46. Stamm, R.B.; Martin, R.P. Quantification of pressure gradients across stenotic valves by Doppler ultrasound. J. Am. Coll. Cardiol. 1983, 2, 707-718. [CrossRef]

47. Warnes, C.A.; Williams, R.G.; Bashore, T.M.; Child, J.S.; Connolly, H.M.; Dearani, J.A.; Del Nido, P.; Fasules, J.W.; Graham, T.P.; Hijazi, Z.M.; et al. ACC/AHA 2008 guidelines for the management of adults with congenital heart disease: A report of the American College of Cardiology/American Heart Association Task Force on Practice Guidelines (Writing Committee to Develop Guidelines on the Management of Adults with Congenital Heart Disease). Developed in Collaboration with the American Society of Echocardiography, Heart Rhythm Society, International Society for Adult Congenital Heart Disease, Society for Cardiovascular Angiography and Interventions, and Society of Thoracic Surgeons. J. Am. Coll. Cardiol. 2008, 52, e143-e263. [PubMed]

48. Saeed, M.; Van, T.A.; Krug, R.; Hetts, S.W.; Wilson, M.W. Cardiac MR imaging: Current status and future direction. Cardiovasc. Diagn. Ther. 2015, 5, 290-310.

49. Hochhegger, B.; de Souza, V.V.S.; Marchiori, E.; Irion, K.L.; Souza, A.S., Jr.; Elias Junior, J.; Rodrigues, R.S.; Barreto, M.M.; Escuissato, D.L.; Mançano, A.D.; et al. Chest magnetic resonance imaging: A protocol suggestion. Radiol Bras 2015, 48, 373-380. [CrossRef]

50. Nayak, K.S.; Nielsen, J.-F.; Bernstein, M.A.; Markl, M.; Gatehouse, P.; Botnar, R.M.; Saloner, D.; Lorenz, C.; Wen, H.; Hu, B.S.; et al. Cardiovascular magnetic resonance phase contrast imaging. J. Cardiovasc. Magn. Reson. 2015, 17, 71. [CrossRef]

51. Knutsen, K.M.; Bae, E.A.; Sivertssen, E.; Grendahl, H. Doppler ultrasound in mitral stenosis. Assessment of pressure gradient and atrioventricular pressure half-time. Acta Med. Scand. 1982, 211, 433-436. [CrossRef]

52. Hatle, L.; Angelsen, B.A.; Tromsdal, A. Non-invasive assessment of aortic stenosis by Doppler ultrasound. Br. Heart J. 1980, 43, 284-292. [CrossRef] [PubMed] 
53. Currie, P.J.; Seward, J.B.; Reeder, G.S.; Vlietstra, R.E.; Bresnahan, D.R.; Bresnahan, J.F.; Smith, H.C.; Hagler, D.J.; Tajik, A.J. Continuous-wave Doppler echocardiographic assessment of severity of calcific aortic stenosis: A simultaneous Doppler-catheter correlative study in 100 adult patients. Circulation 1985, 71, 1162-1169. [CrossRef] [PubMed]

54. Currie, P.J.; Hagler, D.J.; Seward, J.B.; Reeder, G.S.; Fyfe, D.A.; Bove, A.A.; Taji, A.J. Instantaneous pressure gradient: A simultaneous doppler and dual catheter correlative study. J. Am. Coll. Cardiol. 1986, 7, 800-806. [CrossRef]

55. Burstow, D.J.M.; Nishimura, R.A.; Bailey, K.R.; Reeder, G.S.; Holmes, D.R.J.; Seward, J.B.; Tajik, A.J. Continuous Wave Doppler Echocardiographic Measurement of Prosthetic Valve Gradients: A Simultaneous Doppler-Catheter Correlative Study. Circulation 1989, 80, 504-514. [CrossRef] [PubMed]

56. Yeager, M.; Yock, P.G.; Popp, R.L. Comparison of Doppler-derived pressure gradient to that determined at cardiac catheterization in adults with aortic valve stenosis: Implications for management. Am. J. Cardiol. 1986, 57, 644-648. [CrossRef]

57. Ohlsson, J.; Wranne, B. Noninvasive assessment of valve area in patients with aortic stenosis. J. Am. Coll. Cardiol. 1986, 7, 501-508. [CrossRef]

58. Baumgartner, H.; Stefenelli, T.; Niederberger, J.; Schima, H.; Maurer, G. "Overestimation" of catheter gradients by Doppler ultrasound in patients with aortic stenosis: A predictable manifestation of pressure recovery. J. Am. Coll. Cardiol. 1999, 33, 1655-1661. [CrossRef]

59. VanAuker, M.D.; Hla, A.; Meisner, J.S.; Strom, J.A. Simultaneous Doppler/catheter measurements of pressure gradients in aortic valve disease: A correction to the Bernoulli equation based on velocity decay in the stenotic jet. J. Heart Valve Dis. 2000, 9, 291-298. [PubMed]

60. Yamazawa, H. Accuracy of the Doppler-derived pressure gradient in pediatric patients with aortic valvular stenosis: Is the correction for pressure recovery necessary? Hokkaido Igaku Zasshi 2010, 85, 225-231.

61. Eichenberger, A.C.; Jenni, R.; von Schulthess, G.K. Aortic valve pressure gradients in patients with aortic valve stenosis: Quantification with velocity-encoded cine MR imaging. AJR Am. J. Roentgenol. 1993, 160, 971-977. [CrossRef]

62. Lang, R.M.; Badano, L.P.; Mor-Avi, V.; Afilalo, J.; Armstrong, A.; Ernande, L.; Flachskampf, F.A.; Foster, E.; Goldstein, S.A.; Kuznetsova, T.; et al. Recommendations for cardiac chamber quantification by echocardiography in adults: An update from the American Society of Echocardiography and the European Association of Cardiovascular Imaging. Eur. Heart J. Cardiovasc. Imaging 2015, 16, 233-270. [CrossRef] [PubMed]

63. Hioka, T.; Kaga, S.; Mikami, T.; Okada, K.; Murayama, M.; Masauzi, N.; Nakabachi, M.; Nishino, H.; Yokoyama, S.; Nishida, M.; et al. Overestimation by echocardiography of the peak systolic pressure gradient between the right ventricle and right atrium due to tricuspid regurgitation and the usefulness of the early diastolic transpulmonary valve pressure gradient for estimating pulmonary artery pressure. Heart Vessels 2017, 32, 833-842. [PubMed]

64. Fisher, M.R.; Forfia, P.R.; Chamera, E.; Housten-Harris, T.; Champion, H.C.; Girgis, R.E.; Corretti, M.C.; Hassoun, P.M. Accuracy of Doppler echocardiography in the hemodynamic assessment of pulmonary hypertension. Am. J. Respir. Crit. Care Med. 2009, 179, 615-621. [CrossRef] [PubMed]

65. Magnino, C.; Omedè, P.; Avenatti, E.; Presutti, D.; Iannaccone, A.; Chiarlo, M.; Moretti, C.; Gaita, F.; Veglio, F.; Milan, A.; et al. Inaccuracy of Right Atrial Pressure Estimates Through Inferior Vena Cava Indices. Am. J. Cardiol. 2017, 120, 1667-1673. [CrossRef] [PubMed]

66. Janda, S.; Shahidi, N.; Gin, K.; Swiston, J. Diagnostic accuracy of echocardiography for pulmonary hypertension: A systematic review and meta-analysis. Heart 2011, 97, 612-622. [CrossRef] [PubMed]

67. Nogami, M.; Ohno, Y.; Koyama, H.; Kono, A.; Takenaka, D.; Kataoka, T.; Kawai, H.; Kawamitsu, H.; Onishi, Y.; Matsumoto, K.; et al. Utility of phase contrast MR imaging for assessment of pulmonary flow and pressure estimation in patients with pulmonary hypertension: Comparison with right heart catheterization and echocardiography. J. Magn. Reson. Imaging 2009, 30, 973-980. [CrossRef] [PubMed]

68. Marx, G.R.; Allen, H.D. Accuracy and pitfalls of Doppler evaluation of the pressure gradient in aortic coarctation. J. Am. Coll. Cardiol. 1986, 7, 1379-1385. [CrossRef]

69. Houston, A.B.; Simpson, I.A.; Pollock, J.C.; Jamieson, M.P.; Doig, W.B.; Coleman, E.N. Doppler ultrasound in the assessment of severity of coarctation of the aorta and interruption of the aortic arch. Br. Heart J. 1987, 57, 38-43. [CrossRef] 
70. Wisotzkey, B.L.; Hornik, C.P.; Green, A.S.; Barker, P.C.A. Comparison of invasive and non-invasive pressure gradients in aortic arch obstruction. Cardiol. Young 2015, 25, 1348-1357. [CrossRef]

71. Tang, L.; Forbes, T.J.; Du, W.; Zilberman, M.V. Echocardiographic Evaluation of Pressure Gradient across the Stent in Patients Treated for Coarctation of the Aorta. Cong. Heart Dis. 2009, 4, 269-272. [CrossRef]

72. Oshinski, J.N.; Parks, W.J.; Markou, C.P.; Bergman, H.L.; Larson, B.E.; Ku, D.N.; Mukundan, S.; Pettigrew, R.I. Improved measurement of pressure gradients in aortic coarctation by magnetic resonance imaging. J. Am. Coll. Cardiol. 1996, 28, 1818-1826. [CrossRef]

73. Itu, L.; Sharma, P.; Ralovich, K.; Mihalef, V.; Ionasec, R.; Everett, A.; Ringel, R.; Kamen, A.; Comaniciu, D. Non-invasive hemodynamic assessment of aortic coarctation: Validation with in vivo measurements. Ann. Biomed. Eng. 2013, 41, 669-681. [CrossRef] [PubMed]

74. Sotelo, J.A.; Valverde, I.; Beerbaum, P.B.; Greil, G.F.; Schaeffter, T.; Razavi, R.; Hurtado, D.E.; Uribe, S.; Figueroa, C.A. Pressure gradient prediction in aortic coarctation using a computational-fluid-dynamics model: Validation against invasive pressure catheterization at rest and pharmacological stress. J. Cardiovasc. Magn. Reson. 2015, 17, Q78. [CrossRef]

75. Goubergrits, L.; Riesenkampff, E.; Yevtushenko, P.; Schaller, J.; Kertzscher, U.; Hennemuth, A.; Berger, F.; Schubert, S.; Kuehne, T. MRI-based computational fluid dynamics for diagnosis and treatment prediction: Clinical validation study in patients with coarctation of aorta. J. Magn. Reson. Imaging 2015, 41, 909-916. [CrossRef] [PubMed]

76. Mirzaee, H.; Henn, T.; Krause, M.J.; Goubergrits, L.; Schumann, C.; Neugebauer, M.; Kuehne, T.; Preusser, T.; Hennemuth, A. MRI-based computational hemodynamics in patients with aortic coarctation using the lattice Boltzmann methods: Clinical validation study. J. Magn. Reson. Imaging 2017, 45, 139-146. [CrossRef]

77. Chest Pain of Recent Onset: Assessment and Diagnosis I Guidance and Guidelines I NICE. Available online: https:/ / www.nice.org.uk/guidance/cg95 (accessed on 9 August 2018).

78. Deng, Z.; Fan, Z.; Lee, S.-E.; Nguyen, C.; Xie, Y.; Pang, J.; Bi, X.; Yang, Q.; Choi, B.-W.; Kim, J.-S.; et al. Noninvasive measurement of pressure gradient across a coronary stenosis using phase contrast (PC)-MRI: A feasibility study. Magn. Reson. Med. 2017, 77, 529-537. [CrossRef] [PubMed]

79. Nasiraei-Moghaddam, A.; Behrens, G.; Fatouraee, N.; Agarwal, R.; Choi, E.T.; Amini, A.A. Factors affecting the accuracy of pressure measurements in vascular stenoses from phase-contrast MRI. Magn. Reson. Med. 2004, 52, 300-309. [CrossRef]

80. Lum, D.P.; Johnson, K.M.; Paul, R.K.; Turk, A.S.; Consigny, D.W.; Grinde, J.R.; Mistretta, C.A.; Grist, T.M. Transstenotic pressure gradients: Measurement in swine-Retrospectively ECG-gated 3D phase-contrast MR angiography versus endovascular pressure-sensing guidewires. Radiology 2007, 245, 751-760. [CrossRef]

81. Markl, M.; Schnell, S.; Wu, C.; Bollache, E.; Jarvis, K.; Barker, A.J.; Robinson, J.D.; Rigsby, C.K. Advanced flow MRI: Emerging techniques and applications. Clin. Radiol. 2016, 71, 779-795. [CrossRef]

82. Krzanowski, M.; Bodzoń, W.; Dimitrow, P.P. Imaging of all three coronary arteries by transthoracic echocardiography. an illustrated guide. Cardiovasc. Ultrasound. 2003, 1, 16. [CrossRef]

83. Vegsundvåg, J.; Holte, E.; Wiseth, R.; Hegbom, K.; Hole, T. Transthoracic echocardiography for imaging of the different coronary artery segments: A feasibility study. Cardiovasc. Ultrasound. 2009, 7, 58. [CrossRef]

84. Labombarda, F.; Castelnuovo, S.; Goularas, D.; Sirtori, C.R. Status and potential clinical value of a transthoracic evaluation of the coronary arteries. Cardiovasc. Ultrasound. 2016, 14, 5. [CrossRef]

85. Gerhard-Herman, M.D.; Gornik, H.L.; Barrett, C.; Barshes, N.R.; Corriere, M.A.; Drachman, D.E.; Fleisher, L.A.; Fowkes, F.G.R.; Hamburg, N.M.; Kinlay, S.; et al. 2016 AHA/ACC Guideline on the Management of Patients with Lower Extremity Peripheral Artery Disease: A Report of the American College of Cardiology/American Heart Association Task Force on Clinical Practice Guidelines. Circulation 2017, 135, e726-e779. [PubMed]

86. Illig, K.A.; Ouriel, K.; DeWeese, J.A.; Holen, J.; Green, R.M. Measurement of carotid bifurcation pressure gradients using the Bernoulli principle. Cardiovasc. Surg. 1996, 4, 130-134. [CrossRef]

87. De Smet, A.A.; Tetteroo, E.; Moll, F.L. Noninvasive evaluation before and after percutaneous therapy of iliac artery stenoses: The value of the Bernoulli-predicted pressure gradient. J. Vasc. Surg. 2000, 32, 153-159. [CrossRef] [PubMed]

88. Kohler, T.R.; Nicholls, S.C.; Zierler, R.E.; Beach, K.W.; Schubart, P.J.; Strandness, D.E. Assessment of pressure gradient by Doppler ultrasound: Experimental and clinical observations. J. Vasc. Surg. 1987, 6, 460-469. [CrossRef] 
89. Langsfeld, M.; Nepute, J.; Hershey, F.B.; Thorpe, L.; Auer, A.I.; Binnington, H.B.; Hurley, J.J.; Peterson, G.J.; Schwartz, R.; Woods, J.J. The use of deep duplex scanning to predict hemodynamically significant aortoiliac stenoses. J. Vasc. Surg. 1988, 7, 395-399. [CrossRef]

90. Strauss, A.L.; Roth, F.J.; Rieger, H. Noninvasive assessment of pressure gradients across iliac artery stenoses: Duplex and catheter correlative study. J. Ultrasound. Med. 1993, 12, 17-22. [CrossRef]

91. Moftakhar, R.; Aagaard-Kienitz, B.; Johnson, K.; Turski, P.A.; Turk, A.S.; Niemann, D.B.; Consigny, D.; Grinde, J.; Wieben, O.; Mistretta, C.A. Noninvasive measurement of intra-aneurysmal pressure and flow pattern using phase contrast with vastly undersampled isotropic projection imaging. AJNR Am. J. Neuroradiol. 2007, 28, 1710-1714. [CrossRef]

92. Turk, A.S.; Johnson, K.M.; Lum, D.; Niemann, D.; Aagaard-Kienitz, B.; Consigny, D.; Grinde, J.; Turski, P.; Haughton, V.; Mistretta, C. Physiologic and anatomic assessment of a canine carotid artery stenosis model utilizing phase contrast with vastly undersampled isotropic projection imaging. AJNR Am. J. Neuroradiol. 2007, 28, 111-115.

93. Bley, T.A.; Johnson, K.M.; François, C.J.; Reeder, S.B.; Schiebler, M.L.; R Landgraf, B.; Consigny, D.; Grist, T.M.; Wieben, $\mathrm{O}$. Noninvasive assessment of transstenotic pressure gradients in porcine renal artery stenoses by using vastly undersampled phase-contrast MR angiography. Radiology 2011, 261, 266-273. [CrossRef] [PubMed]

94. Baumgartner, H.; Bonhoeffer, P.; De Groot, N.M.S.; de Haan, F.; Deanfield, J.E.; Galie, N.; Gatzoulis, M.A.; Gohlke-Baerwolf, C.; Kaemmerer, H.; Kilner, P.; et al. ESC Guidelines for the management of grown-up congenital heart disease (new version 2010) The Task Force on the Management of Grown-up Congenital Heart Disease of the European Society of Cardiology (ESC). Eur. Heart J. 2010, 31, 2915-2957. [PubMed]

95. VanAuker, M.D.; Chandra, M.; Shirani, J.; Strom, J.A. Jet eccentricity: A misleading source of agreement between Doppler/catheter pressure gradients in aortic stenosis. J. Am. Soc. Echocardiogr. 2001, 14, 853-862. [CrossRef] [PubMed]

96. Ha, H.; Kim, G.B.; Kweon, J.; Huh, H.K.; Lee, S.J.; Koo, H.J.; Kang, J.-W.; Lim, T.-H.; Kim, D.-H.; Kim, Y.-H.; et al. Turbulent Kinetic Energy Measurement Using Phase Contrast MRI for Estimating the Post-Stenotic Pressure Drop: In Vitro Validation and Clinical Application. PLoS ONE 2016, 11, e0151540. [CrossRef] [PubMed]

97. Gatehouse, P.D.; Keegan, J.; Crowe, L.A.; Masood, S.; Mohiaddin, R.H.; Kreitner, K.-F.; Firmin, D.N. Applications of phase-contrast flow and velocity imaging in cardiovascular MRI. Eur. Radiol. 2005, 15, 2172-2184. [CrossRef] [PubMed]

98. Rich, J.D.; Shah, S.J.; Swamy, R.S.; Kamp, A.; Rich, S. Inaccuracy of Doppler Echocardiographic Estimates of Pulmonary Artery Pressures in Patients with Pulmonary Hypertension: Implications for Clinical Practice. Chest 2011, 139, 988-993. [CrossRef] [PubMed]

99. Jensen, J.A.; Munk, P. A new method for estimation of velocity vectors. IEEE Trans. Ultrason. Ferroelectr. Freq. Control 1998, 45, 837-851. [CrossRef]

100. Olesen, J.B.; Villagomez-Hoyos, C.A.; Moller, N.D.; Ewertsen, C.; Hansen, K.L.; Nielsen, M.B.; Bech, B.; Lonn, L.; Traberg, M.S.; Jensen, J.A. Noninvasive Estimation of Pressure Changes Using 2-D Vector Velocity Ultrasound: An Experimental Study With In Vivo Examples. IEEE Trans. Ultrason. Ferroelectr. Freq. Control 2018, 65, 709-719. [CrossRef]

101. Brandt, A.H.; Hansen, K.L.; Ewertsen, C.; Holbek, S.; Olesen, J.B.; Moshavegh, R.; Thomsen, C.; Jensen, J.A.; Nielsen, M.B. A Comparison Study of Vector Velocity, Spectral Doppler and Magnetic Resonance of Blood Flow in the Common Carotid Artery. Ultrasound. Med. Biol. 2018, 44, 1751-1761. [CrossRef]

102. Holbek, S.; Hansen, K.L.; Bouzari, H.; Ewertsen, C.; Stuart, M.B.; Thomsen, C.; Nielsen, M.B.; Jensen, J.A. Common Carotid Artery Flow Measured by 3-D Ultrasonic Vector Flow Imaging and Validated with Magnetic Resonance Imaging. Ultrasound. Med. Biol. 2017, 43, 2213-2220. [CrossRef]

(C) 2018 by the authors. Licensee MDPI, Basel, Switzerland. This article is an open access article distributed under the terms and conditions of the Creative Commons Attribution (CC BY) license (http:/ / creativecommons.org/licenses/by/4.0/). 